\title{
Coronary arterial fistulas
}

INSERM

\section{Source}

INSERM. (1999). Orphanet: an online rare disease and orphan drug data base. Coronary

arterial fistulas. ORPHA:2041

Coronary arterial fistulas are a connection between one or more of the coronary arteries and a cardiac chamber or great vessel. 